Selected Combustion Problems, 2

Transport Phenomena; Ignition; Altitude Behaviour and Scaling of Aeroengines. M. W. Thring (Senior Editor). (AGARD Combustion Colloquium, Liège, Belgium, December 5 to 9 , 1955.) Pp. viii + 495. (London: Butterworths Scientific Publications ; New York: Interscience Publishers, Inc., 1956.) $90 s$. ; 12.50 dollars.

$\mathrm{T}$ HIS is the record of the combustion colloquium, held at Liège in December 1955. Eighteen papers were presented and discussed at some length, the languages used being English and French. Abstracts are rendered in both tongues with occasionally interesting results, and a small subject index of doubtful value is appended.

The papers are, as the main title of the book suggests, on chosen aspects of combustion. The choice naturally has regard to the interests of aeronautical scientists, and the sub-title rather incompletely indicates group headings. The author's aim is generally to survey, and little new experimental work is presented.

There is no doubt that colloquia of this nature are of value in assessing the current state of knowledge and in defining those problems that most clearly call for study. It is good to see evidence that time was allowed for extended discussion.

As to how far the record is of permanent value on the library shelf is another matter. A possible view is that the practical success of the meeting will be measured by the speed with which the papers and discussion become out-dated. Meanwhile, those who are concerned with aero engines (including rocket motors) and their fuels, fundamentally considered, will find ample material for consideration within these pages.

J. H. Burgoyne

The Alimentary Tract of the Ruminant By David Benzie and Dr. A. T. Phillipson. Pp. $24+54$ plates. (Edinburgh and London: Oliver and Boyd, Ltd., 1957.) 27s. 6d. net.

NVESTIGATION of the gut of the ruminant during 1 the past twenty years has made the chemical changes which go on within the stomach reasonably plain. This is not, however, true of the mechanical activity of the alimentary tract and there is still a considerable degree of doubt as to the way in which food is sorted into that fraction which goes to the rumen and that fraction which is passed along the cesophageal groove to the abomasum, and as to the muscular movements which play a part in the belching which these animals use in order to get rid of the gas produced during ruminal digestion. A relatively new approach to these problems has been made with the use of radiographic studies, a series of which is reported in this volume. Part of the work was done in the Department of Physiology of the Rowett Research Institute, and part in the Department of Anatomy at the University of Manchester. The animals appear to withstand the effect of radiography well and not to be much affected by this experimental method. The book consists largely of an atlas of 54 plates, most of which contain several X-ray photographs of the alimentary tract of young animals (lambs, calves, kids) fed a barium meal. The movements of the gut are obviously complex, but among the interesting points which the series of photographs makes plain is the confirmation of the extra-ruminal contraction described by Weiss as the basis of the belching mechanism. Since the work was carried out predominantly on young animals mainly fed on milk, the part played by the chambers of the stomach other than the abomasum is not made plain, though an interpretation of the activity of the omasum is given. There is every expectation of this most promising method leading to clarification of the muscular movements carried out by each part of the stomach in the alimentary tract of these animals.

A. Graham

\section{Structural Psychology}

De Humani Mentis Fabrica. By D. and K. StanleyJones. Pp. viii +180 . (Bristol : John Wright and Sons, Ltd., 1957.) $21 s$.

THE authors of this book define structural psychology as "a system of psychology erected upon the basic sciences of anatomy and physiology" (page v) and further state that "the contribution which structural psychology has to make to the major problem of philosophy has been to prove that the structure of the mind and the strueture of the brain are sufficiently alike in every known point of comparison to warrant the statement that they are identical. By proof of the identity of structure the hypothesis is justified that there is an identity both of location and substance" (p. 160).

It is suggested that emotion originated in palæolithic times when man lived mainly in caves, and these were conditioned to "lust and feeding in the warmth of the night, aggression in the outside cold of the day". Aggression is associated with oral biting and massive discharge of the orthosympathetic system, and in balanced antagonism with oral sucking and the parasympathetic system. Obstruction of the sucking leads to a mass discharge of the orthosympathetic with oral biting.

These basic reactions become associated with the mother, envisaged by the child as the bad mother when it is unsatisfied and the good mother when it is. From her the emotions are transferred to the father and so to society.

It is impossible to describe the whole of the authors' arguments in a few words. They link physiology ingeniously with psychological concepts, but their system is not completely new and is mainly a fresh arrangement of Freudian psychology and organic theories. It should prove interesting to those psychologists interested in physiology and those physiologists psychologically orientated.

The book is clearly printed on non-shiny paper, the style is lucid and should be understood by educated readers even if unfamiliar with the material. There is an excellent index and glossary.

\section{Intermediate Physics}

By Dr. C. J. Smith. Fourth edition. Pp. xiii + 1322. (London: Edward Arnold (Publishers), Ltd., 1957.) $45 s$. net.

OVER some twenty-five years the successive editions of this standard intermediate text-book have proved their value. There are 300 more pages than in the 1947 edition, and the extensive rewriting to clarify points which students always find difficult, with the addition of material to bring it well up to the requirements of a good scholarship candidate, will certainly increase even further the number of people who will use it happily and with success. Noteworthy additions are the fuller treatment of 